\title{
FEM Analysis for Sealing Performance of Hydraulic Pressure Brake Hose Caulking Portion*
}

\author{
Nao-Aki NODA**, Shinpei YOSHIMURA**, Hirofumi KAWAHARA** \\ and Masakazu TSUYUNARU** \\ **Department of Mechanical Engineering, Kyushu Institute of Technology, \\ 1-1 Sensui-cho, Tobata-ku, Kitakyushu-shi, 804-8550 Japan \\ E-mail: noda@mech.kyutech.ac.jp
}

\begin{abstract}
Usually, automobile brake and power steering hoses have been developed through investigating several actual prototype hoses experimentally. Recently, high durability has been required for brake hose because periodic renewing has not been requested anymore for personal automobiles. In this study, FEM stress analysis has been applied to the crimped portion of hydraulic brake hose in order to promote developing the automobile hoses more efficiently. It is found that the large normal stress $\sigma_{\mathrm{n}}$, which may control the sealing performance, appears at the crimped portion between the nipple and inner rubber. The results suggest that several grooves putting at the surface of nipple are effective for causing large $\sigma_{n}$, which may improve the sealing performance and hose lifetime. The effect of compression set of the rubber on the sealing performance is investigated, and the lifetime of hydraulic brake hose is estimated form the maximum stress appearing at the groove on the nipple.
\end{abstract}

Key words: Stress Analysis, Finite Element Method, Sealing Performance, Brake Hose, Life Estimation

\section{Introduction}

In automobiles to conduct the oil pressure generated by the master cylinder to the brake, hydraulic brake hoses are installed between the body and chassis as shown in Fig.1 (a). In recent years, brake hoses have to be arranged in a quite smaller space by introducing anti-lock brake system as well as complex link mechanism for high grade suspension. The brake hoses are supposed to be always flexible since they are subjected to complex external loads such as lateral vibration from the road, torsion from steering wheel, and impact oil pressure during braking. Although those brake hoses were changed in every few years previously, a new regulation enacted in 1995 has not requested this regular renewing anymore for personal automobiles ${ }^{(1)}$, and therefore, high durability of brake hose is now necessary. In addition, to pursuit comfortable driving, low expansion of brake hoses is also requested in terms of quick response for braking ${ }^{(2)}$.

The brake hose consists of inner rubber, reinforced layer, and outer rubber as shown in Fig. 1 (b). Caulking of brake hose is realized through crimping socket after inserting brake hose as shown in Fig.1 (c). Since the rubber material has high flexibility without volume change, high compressible stresses appear between the nipple and inner rubber. In other words, high sealing performance may be realized by the incompressibility of the rubber at the caulking portions. If the brake hosed loses the flexibility after used many years, the brake oil goes into the interface between the nipple and inner rubber and accumulated in the

${ }^{*}$ Received 12 Apr., 2011 (No. T2-08-0386) Japanese Original : Trans. Jpn. Soc. Mech. Eng., Vol.74, No.748, A (2008), pp.1538-1543 (Received 1 May, 2008) [DOI: 10.1299/jmmp.5.484]

Copyright (C) 2011 by JSME 
reinforcing layers, which may cause trouble of brake system (see the green arrow in Fig.1(c)).

Usually, those automobile brake hose were developed experimentally by evaluating several different rubber and several shapes of crimping socket spending time and effort ${ }^{(2)}$. In this study, therefore, stress analysis by FEM will be performed for the crimped portion of hydraulic pressure brake hose in order to promote developing automobile hoses more efficiently. Here, we will focus on the stress between the nipple and inner rubber because that may contribute preventing the oil penetration.

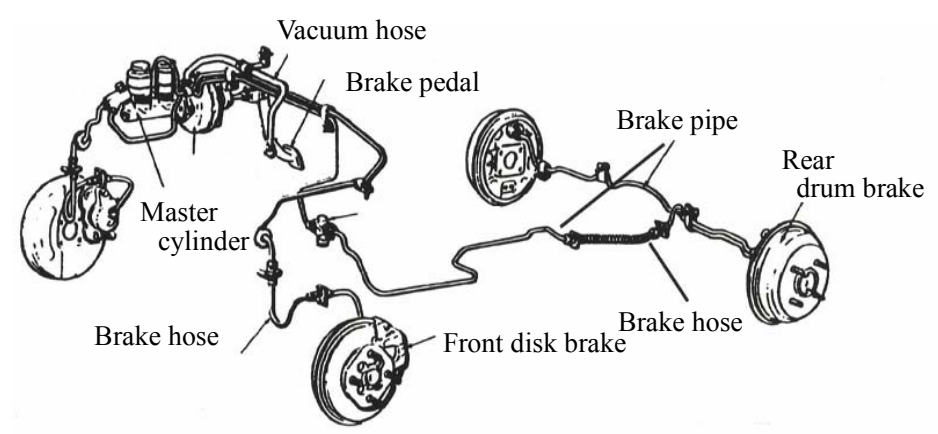

(a) Brake hose in automobiles

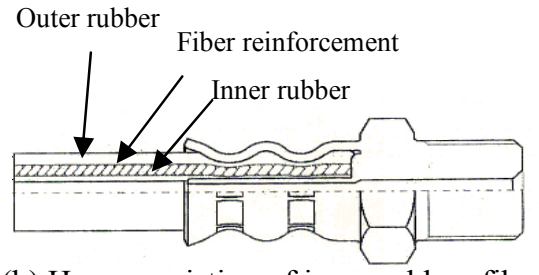

(b) Hose consisting of inner rubber, fiber reinforcement and outer rubber

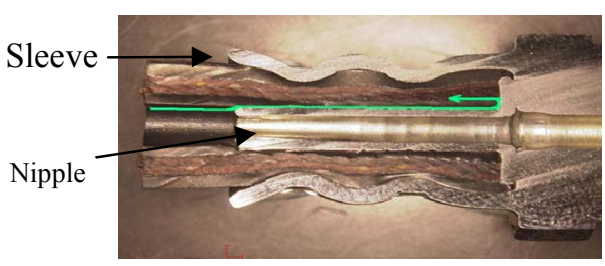

(c) Sockets consisting of nipple and sleeve

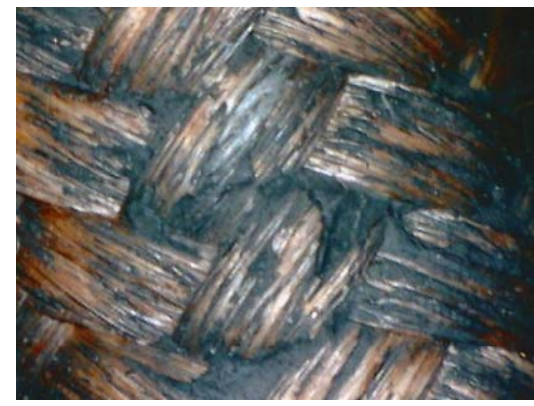

(d) Net structure of fiber reinforcement

Fig. 1 Hydraulic brake hose

\section{Method of Analysis}

\subsection{How to evaluate the sealing performance}

Figure 2 shows the stress-strain relations for inner and outer rubbers. It is known that the stress-strain relations of rubbers may be expressed by using Mooney-Rivlin material model, Ogden material model, or Arruda-Boyce material model. In this study, Arruda-Boyce material model is applied as shown in Fig.2.

The reinforced layer is composed of a complicated net structure of Polyvinyl Alcohol (PVA) as shown in Fig.1 (d), which is not suitable to be expressed as distinct fiber models. 
In this study, therefore, the reinforced layer is modeled as an anisotropic elastic material whose elastic constants are $E_{r}, E_{\theta}=E_{z}, v_{r \theta}, v_{\theta z}, v_{z r}$. Then, most suitable values of those elastic constants are determined from the displacement at the caulking portion. Here we assume that these three layers are bonded completely, and the coefficients of friction are 0.3 for the interfaces between the outer rubber and sleeve, and between the inner rubber and nipple.

Table 1 shows materials and elastic constants of each layer. Here, four nodes axi-symmetric elements are applied as shown in Fig.3. We assume that the displacement in the $\mathrm{z}$-direction at the right end is fixed. The nipple is treated as a rigid body because the deformation is found to be negligible. The displacements in the r-direction are applied at the

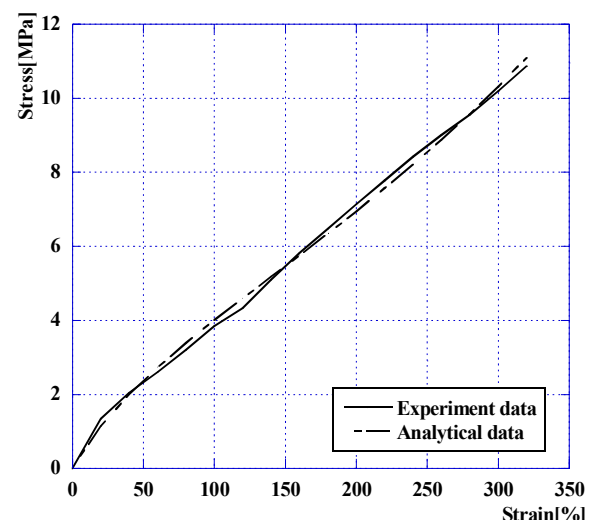

(a) Inner rubber

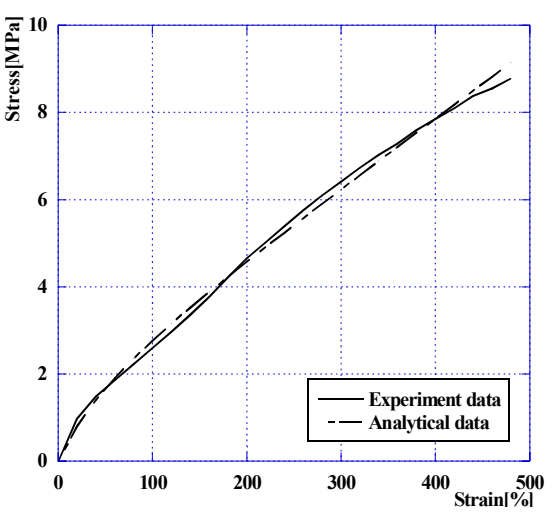

(b) Outer rubber

Fig. 2 Stress strain relation of the rubber

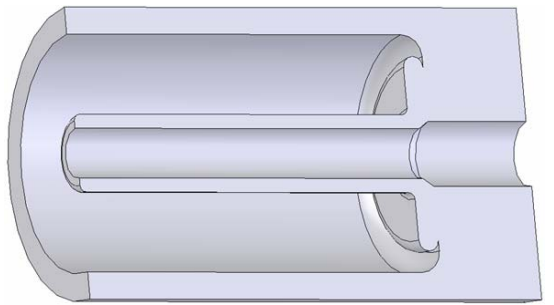

(a) Nipple without groove

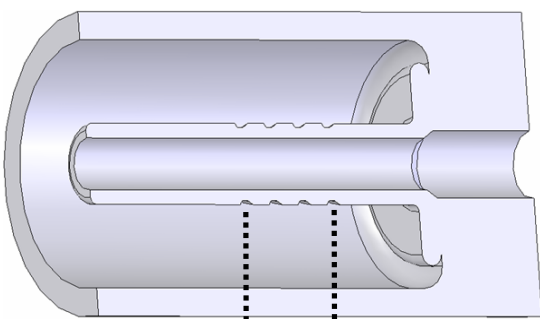

(b) Nipple with four grooves

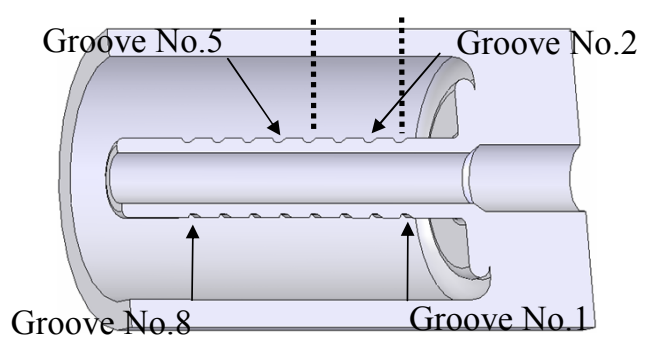

(c) Nipple with eight grooves 


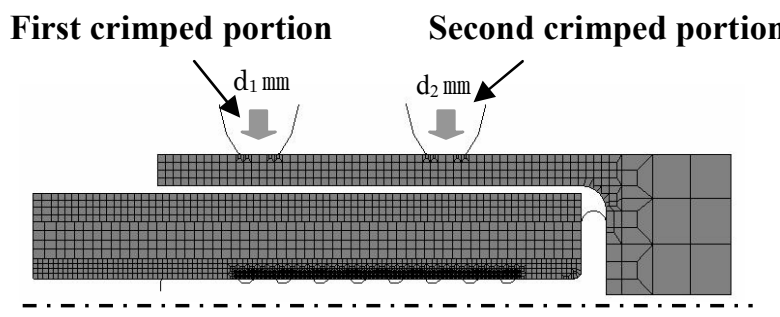

(d) FEM mesh

Fig.3 FEM model for crimping

Table 1 Material data used in FEM analysis

\begin{tabular}{|c|c|c|c|}
\hline & Material & $\begin{array}{l}\text { Young's } \\
\text { modulus } \\
{[\mathrm{MPa}]}\end{array}$ & $\begin{array}{l}\text { Poisson's } \\
\text { ratio }\end{array}$ \\
\hline Outer rubber & EPDM & $\begin{array}{c}\text { Use of Fig. } 2 \\
\text { data }\end{array}$ & $\begin{array}{c}\text { Use of Fig. } 2 \\
\text { data }\end{array}$ \\
\hline Inner rubber & EPDM & $\begin{array}{c}\text { Use of Fig. } 2 \\
\text { data }\end{array}$ & $\begin{array}{c}\text { Use of Fig.2 } \\
\text { data }\end{array}$ \\
\hline $\begin{array}{c}\text { Fiber reinforcement } \\
\text { in the r-direction }\end{array}$ & PVA & $\begin{array}{c}40 \\
\text { (See Table 2) }\end{array}$ & $\begin{array}{c}0.2 \\
\text { (See Table 2) }\end{array}$ \\
\hline $\begin{array}{c}\text { Fiber reinforcement } \\
\text { in the } \theta \text { - and } \\
\text { z-directions }\end{array}$ & PVA & $\begin{array}{c}100 \\
(\text { See Table 2) }\end{array}$ & $\begin{array}{c}0.2 \\
\text { (See Table 2) }\end{array}$ \\
\hline Sleeve & $\mathrm{S} 10 \mathrm{C}$ & 207000 & 0.29 \\
\hline $\begin{array}{l}\text { Nipple and } \\
\text { Crimping tool }\end{array}$ & \multicolumn{3}{|c|}{ Rigid body } \\
\hline
\end{tabular}

first and second caulked portions by a caulking machine with the dimensions of $\mathrm{d}_{1} \mathrm{~mm}$ and $\mathrm{d}_{2} \mathrm{~mm}$, respectively. Sealing performance of brake hose may be evaluated by the normal stress appearing between the nipple and the inner rubber. Three types of nipples are considered, that is, no groove, four grooves, and eight grooves.

\subsection{How to evaluate the sealing performance for old brake hose}

Figure 4 (a) shows an example of permanent deformation after used many years. In this study, we will investigate the effect of this permanent deformation on the sealing performance. Here, we assume the initial shape of the model as show in Fig. 4 (b). Then, the FEM analysis is performed by applying the displacement at the crimped portions. Here, we assume the inner rubber, reinforcing layer, and the outer rubber have the same elastic properties of new materials.

Figure 5 (a), (b) shows the results of compressive permanent deformation of inner rubber and outer rubber based on JIS K 6262 . In this experiment, initial $25 \%$ strain is applied to the JIS test specimen, and then the strain is removed. After 30 minutes past, the strain is measured. Then, the compression set rate is calculated by the following equation.

$$
C s=\frac{t_{0}-t_{2}}{t_{0}-t_{1}} \times 100
$$




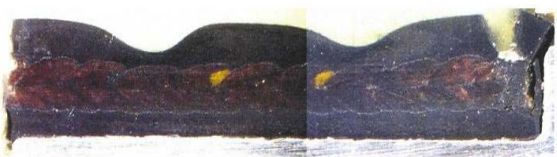

(a) Brake hose used many years

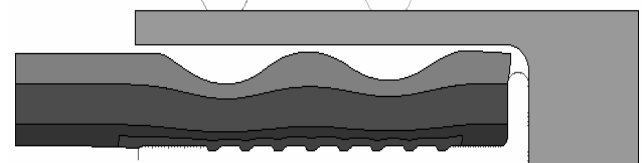

(b) Shape of re-crimped model

(Compression set rate $80 \%$ )

Fig.4 Actual shape and re-crimped model

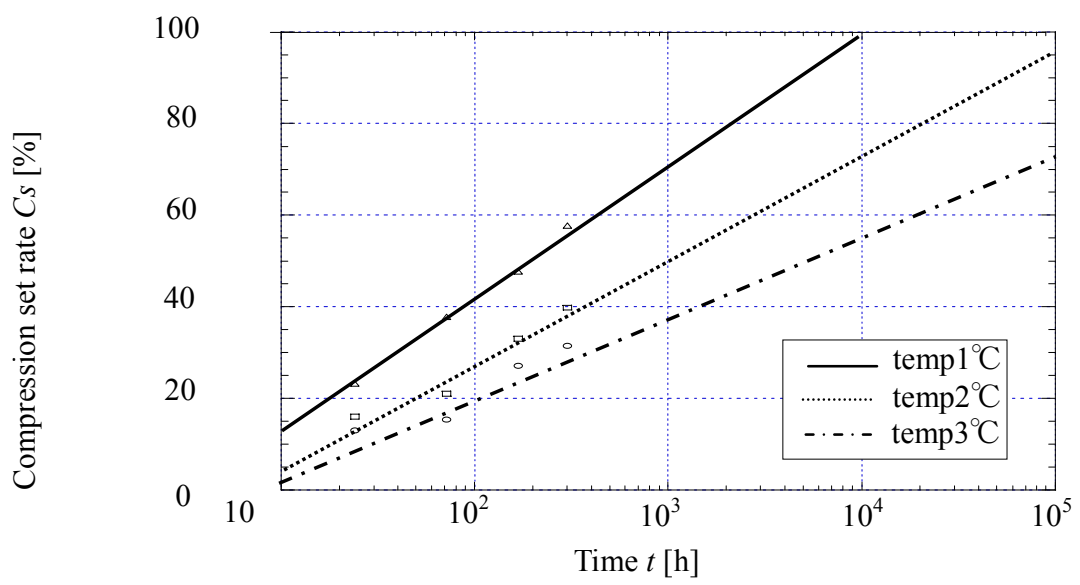

(a) Inner rubber

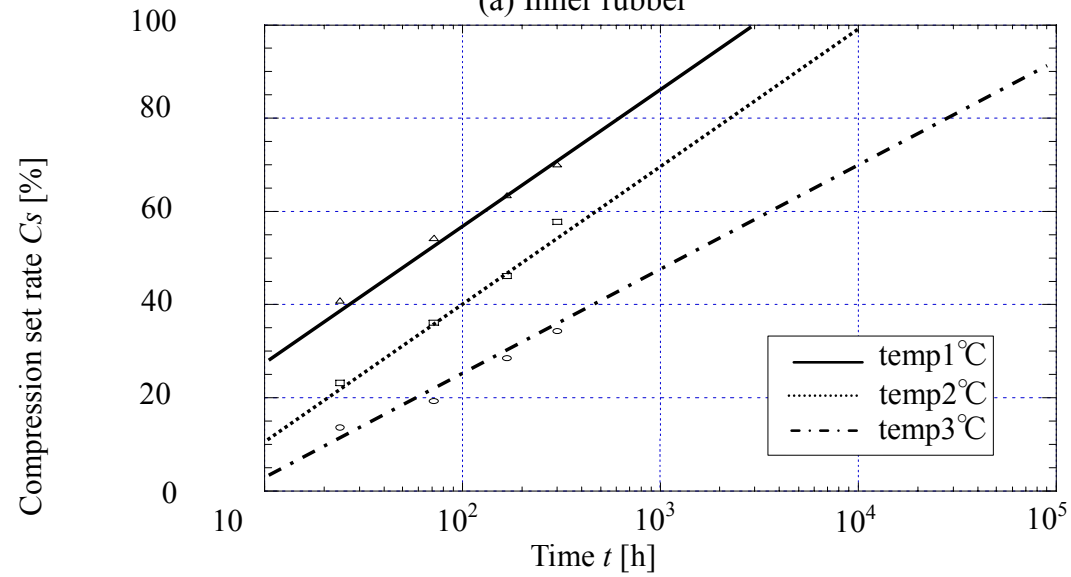

(b) Outer rubber

Fig.5 Experimental results of compression set

Here $C s$ is the compression set rate, $t_{0}$ is the test specimen thickness, $t_{1}$ is the spacer thickness, and $t_{2}$ is the thickness at $30 \mathrm{~min}$, after removing the compressive load. For example $C s=100 \%$ means that the elasticity of rubber is completely lost and restoration is $0 \%$. In this case therefore the sealing performance cannot be expected. Figure 5 shows that the compression set rate is almost in proportional to the logarithmic time in each temperature.

\section{Normal stress on the caulked portion}

As shown in Fig. 6 (a) two cross sections are experimentally examined at the first and second calked portions for eight groove model. Figure 6 (b) shows the first caulking portion at A-A' section, and Fig. 6 (c) shows the second caulking portion B-B' section. Table 2 shows the thicknesses of three layers obtained with varying material constants of reinforced 
layers in FEM. The error is indicated in the parenthesis from the real picture in Fig.6. In Table 2, the experimental values are average values from the data of 36 divisions varying largely in the circumferential direction. It is found that the values $E_{r}=40[\mathrm{MPa}]$, $E_{z}=E_{\theta}=100[\mathrm{MPa}], v_{r \theta}=v_{z r}=v_{\theta z}=0.2$ are most suitable since the thicknesses coincide with the experimental results within $10 \%$. Poisson's ratio is simply assumed as $v_{r \theta}=v_{\theta z}=v_{z r}=0.2$ since the effect is smaller. In the following discussion we will use those values of anisotropic elastic body for the reinforced layer.

It should be noted that Fig.6 (b) shows the cross section A-A' excluding nipple groove but Fig.6 (c) shows the cross section B-B' including nipple groove (see Fig.6(a)). The error in Table 2 is however estimated on the cross section neglecting the dimension of the groove.

Figure 7 indicates the principal strains for three models, that is, no groove, four groove, and eight grooves models. The maximum strain is about $60 \%$ for both no groove, and four groove models. For eight groove model the maximum strain $100 \%$ appears at No.8 grooves because the first caulking portion is just above the No.8 grooves. The reason why the maximum strain appears near No.8 groove is that first caulked potion is just above the groove. Since the inner rubber may go out from the socket, the large strain appears at the left, and of the groove as shown in Fig.7 (c).

Figure 8 shows the normal stress $\sigma_{\mathrm{n}}$ appearing between inner rubber and nipple. The red solid line shows the results of no groove, the blue solid line shows the results of four grooves, and the dashed line shows the results of eight grooves. From Fig. 8 it is found that values of the normal stress $\sigma_{\mathrm{n}}$ is not changed at the same position of the different models. The maximum normal stress $\sigma_{\mathrm{n}}$ for eight groove models is larger than the maximum $\sigma_{\mathrm{n}}$ for four groove models. The largest the normal stress $\sigma_{\mathrm{n}}$ at the No.8 groove may be useful for prevent oil leakage. It may be concluded that the result of no groove and 4 groove models can be estimated from the result of 8 groove models. The present analysis suggests that groove may cause high sealing performance since high stress $\sigma_{\mathrm{n}}$ appears on the grooves.

Table 2 Thickness of three layers

(a) First crimped portion

\begin{tabular}{|c|c|c|c|c|c|}
\hline $\begin{array}{c}E_{\mathrm{r}} \\
{[\mathrm{MPa}}\end{array}$ & $\begin{array}{c}E_{\theta}=E_{\mathrm{s}} \\
{[\mathrm{MPa}]}\end{array}$ & & $\begin{array}{l}\text { Inner } \\
\text { rubber }\end{array}$ & Reinforcement & $\begin{array}{l}\text { Outer } \\
\text { rubber }\end{array}$ \\
\hline \multirow{2}{*}{40} & \multirow{2}{*}{100} & Thickness [mm] & 0.436 & 1.044 & 0.461 \\
\hline & & Error $\quad[\%]$ & 4.80 & 3.96 & -6.71 \\
\hline \multirow{2}{*}{40} & \multirow{2}{*}{80} & Thickness [mm] & 0.43 & 1.03 & 0.483 \\
\hline & & Error & 6.11 & 5.24 & -11.8 \\
\hline \multirow{2}{*}{60} & \multirow{2}{*}{100} & Thickness [mm] & 0.404 & 1.103 & 0.437 \\
\hline & & Error $[\%]$ & 11.79 & -1.47 & -1.16 \\
\hline \multirow{2}{*}{40} & \multirow{2}{*}{120} & Thickness [mm] & 0.444 & 1.055 & 0.445 \\
\hline & & Error $\quad[\%]$ & 3.06 & 2.94 & -3.01 \\
\hline \multirow{2}{*}{60} & \multirow{2}{*}{120} & Thickness [mm] & 0.415 & 1.11 & 0.421 \\
\hline & & Error $\quad[\%]$ & 9.39 & -2.12 & 2.55 \\
\hline \multicolumn{2}{|c|}{ Experiment } & Thickness [mm] & 0.458 & 1.087 & 0.432 \\
\hline
\end{tabular}

(b) Second crimped portion

\begin{tabular}{|c|c|c|c|c|c|}
\hline $\begin{array}{c}E_{\mathrm{r}} \\
{[\mathrm{MPa}]}\end{array}$ & $\begin{array}{c}E_{\theta}=E_{\mathrm{s}} \\
{[\mathrm{MPa}]}\end{array}$ & & $\begin{array}{l}\text { Inner } \\
\text { rubber }\end{array}$ & Reinforcement & $\begin{array}{l}\text { Outer } \\
\text { rubber }\end{array}$ \\
\hline \multirow{2}{*}{40} & \multirow{2}{*}{100} & Thickness $[\mathrm{mm}]$ & 0.657 & 1.147 & 0.506 \\
\hline & & Error & 10.1 & -9.87 & 0.20 \\
\hline \multirow{2}{*}{40} & \multirow{2}{*}{80} & Thickness [mm] & 0.66 & 1.133 & 0.531 \\
\hline & & Error & 9.71 & -8.52 & -4.73 \\
\hline \multirow{2}{*}{60} & \multirow{2}{*}{100} & Thickness [mm] & 0.635 & 1.201 & 0.483 \\
\hline & & Error & 13.13 & -15.0 & 4.73 \\
\hline \multirow{2}{*}{40} & \multirow{2}{*}{120} & Thickness [mm] & 0.66 & 1.16 & 0.487 \\
\hline & & Error & 9.71 & -11.1 & 3.94 \\
\hline \multirow{2}{*}{60} & \multirow{2}{*}{120} & Thickness [mm] & 0.646 & 1.207 & 0.468 \\
\hline & & Error $\quad[\%]$ & 11.63 & -15.6 & 7.69 \\
\hline \multicolumn{2}{|c|}{ Experiment } & Thickness $[\mathrm{mm}]$ & 0.731 & 1.044 & 0.507 \\
\hline
\end{tabular}




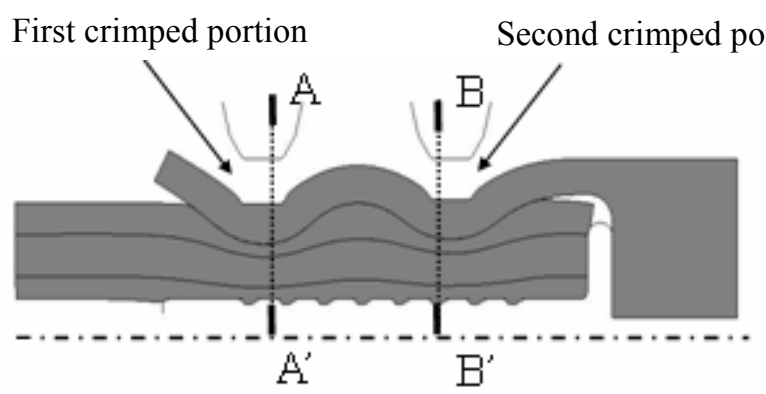

(a) Positions of cross section
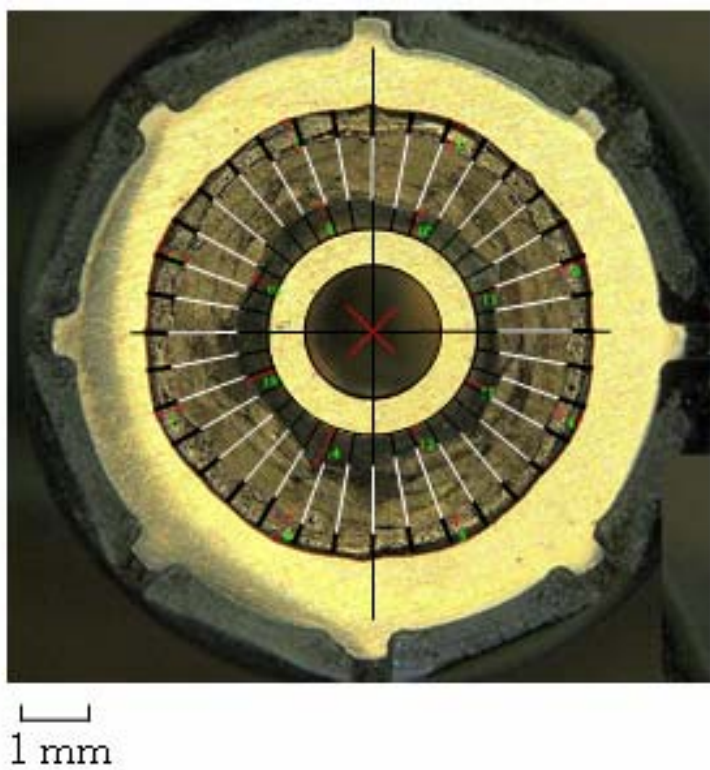

(b) Picture of first caulked portion A-A'

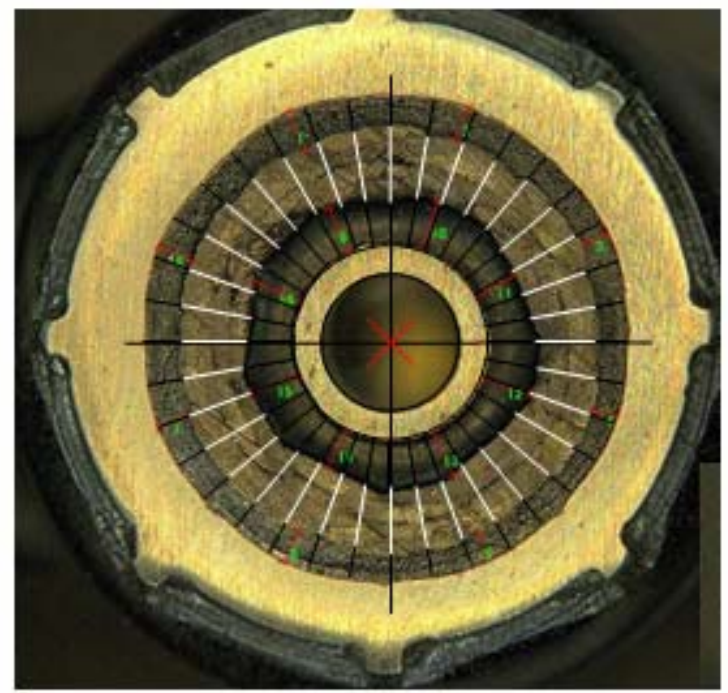

$1 \mathrm{~mm}$

(c) Picture of second caulked portion B-B'

Fig. 6 Cross section at crimped portions 


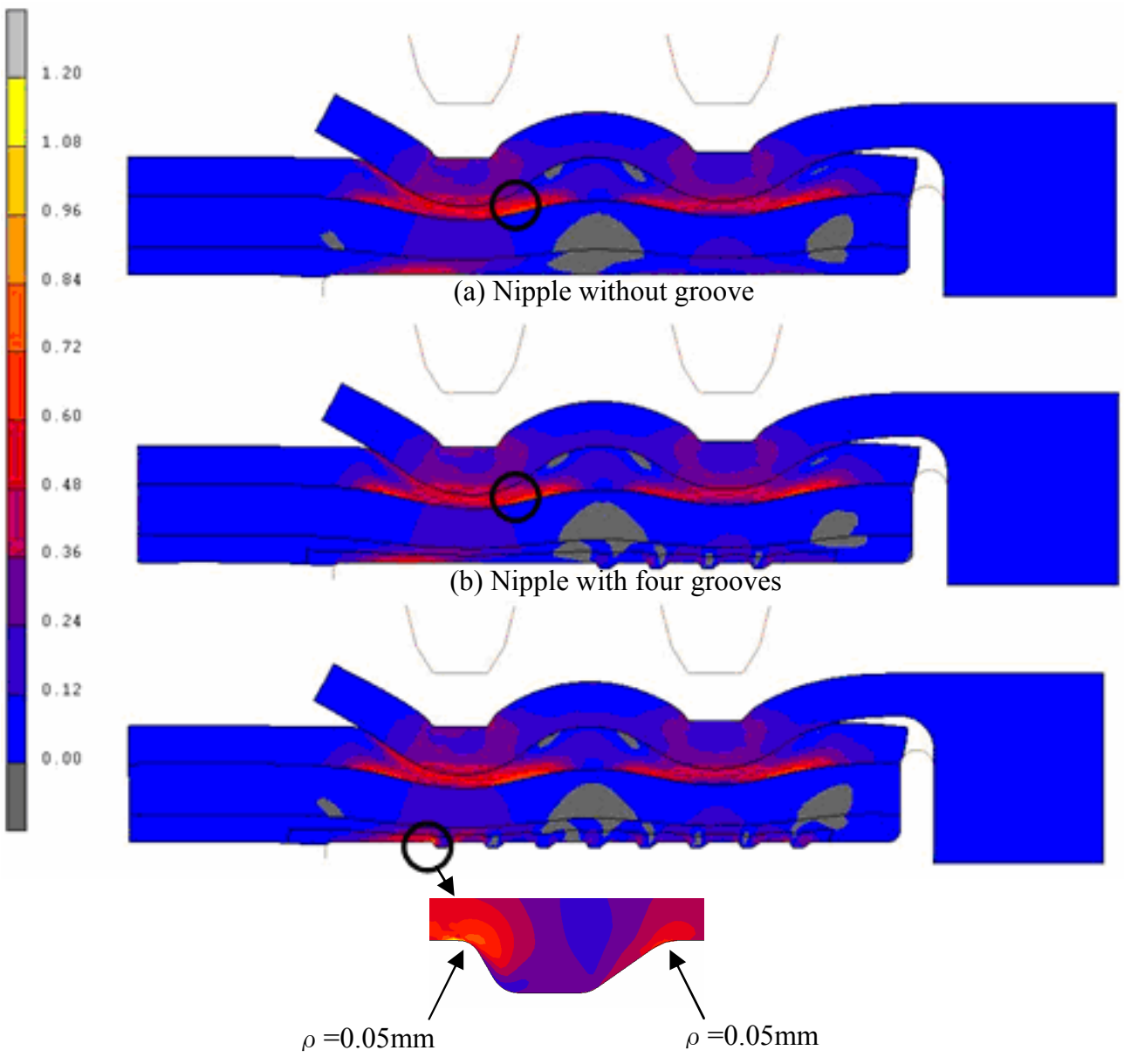

(c) Nipple with eight grooves

Fig. 7 Principal strain distributions

The experimental results also indicate that eight groove model has better sealing performance than the ones of four groove and no groove models. Figure 8 show that eight groove model has larger $\sigma_{\mathrm{n}}$ than that of four groove model. It should be noted that as shown in Fig.7 (c), the groove considered in this study has root radius $0.05 \mathrm{~mm}$. Since the real grooves are usually formed by rolling, the root radius tends to become larger after manufacturing a lot of nipple by using the same rolling dies.

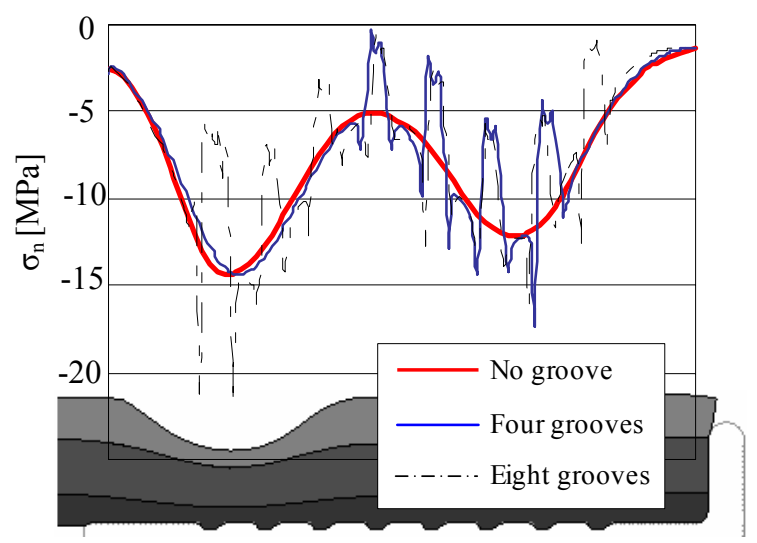

Fig.8 Stress distributions between inner rubber and nipple 


\section{Lifetime estimation of the brake hose}

Although several factors may affect the sealing performance of the brake hose, the permanent deformation caused by heat aging is regarded as a main factor controlling the rubber deterioration. Then the lifetime estimation is attempted by using the experimental results of compression set in Fig.5. Figure 9 shows the results of normal stress $\sigma_{\mathrm{n}}$ between the nipple and inner rubber after re-crimping the old brake hose. Here we assume the amount of permanent deformations as $0 \%, 40 \%, 80 \%$ for the inner rubber, reinforcing layer and outer rubber. Since the mechanical properties of old rubber are unknown, the ones of new rubber are assumed.

The dashed line shows the results of no permanent deformation, that is a new brake hose. The red solid line shows the results of $40 \%$ permanent deformation, and the black solid line shows the results of $80 \%$ permanent deformation. When the permanent deformation is $80 \%$, the normal stress is only about $20 \%$ of the value of no permanent deformation, and therefore may deteriorate sealing performance seriously. Figure 10 shows Arrhenius plot of the inner rubber. The Arrhenius equation (2) is usually used to express chemical reactions including rubber's deterioration as show in Fig. 5 (a).

$$
\log (\alpha \times t)=a\left(\frac{1}{T} \times 10^{3}\right)-b
$$

In Figure 10, the solid line shows the results of $\alpha=1$ and the broken line shows the $\alpha=10$ for Arrhenius equation. Here, $\alpha$ is safety factor to evaluate lifetime, $t$ is lifetime for rubber, $T$ is temperature of rubber [Kelvin], and $a$ and $b$ are constants which should be determined from the results of compression experiment. In this study the lifetime is defined as the time when the permanent deformation is $80 \%$ because the normal stress between inner rubber and nipple decreases significantly. It is assumed that the permanent deformations in the inner rubber, reinforcing layer and outer rubber are always in the same ratio. Then, the lifetime is estimated with focusing on the permanent deformation of the inner rubber.

Table 3 shows the estimated lifetime for the temperature $20 \sim 120^{\circ} \mathrm{C}$. The safety factor is assumed for $\alpha=1$ and $\alpha=10$. It is known that the lifetime of the rubber for $120^{\circ} \mathrm{C}$ is about 70 hour, which is $1 / 4$ of the time 275 hour when $\alpha=1$. Therefore it may be concluded that the real lifetime can be roughly estimated by putting $\alpha=4 \sim 5$.

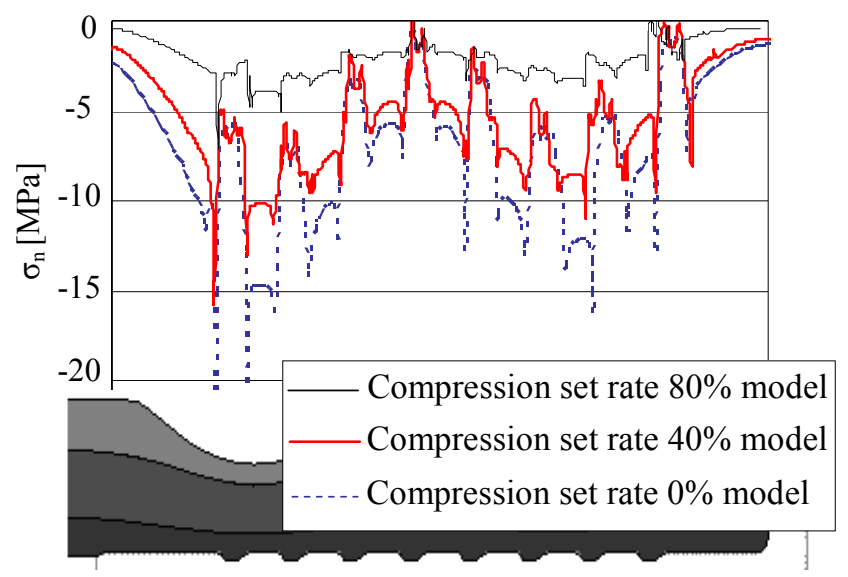

Fig. 9 Analysis result of re-crimped model 
Table 3 Life estimation of brake hose

\begin{tabular}{|c|c|c|}
\hline \multicolumn{3}{|c|}{ Hose life (Safety rate 1) } \\
\hline \begin{tabular}{|l|} 
Average hose temperature $\left({ }^{\circ} \mathrm{C}\right)$ \\
\end{tabular} & Life time $(\mathrm{h})$ & Life time (year) \\
\hline 120 & 275 & 0.031 \\
\hline 100 & 2104 & 0.240 \\
\hline 80 & 28023 & 3.199 \\
\hline 60 & 509330 & 58.143 \\
\hline 40 & 13410273 & 1530.853 \\
\hline 20 & 551814398 & 62992.511 \\
\hline \multicolumn{3}{|c|}{ Hose life (Safe ty rate 10) } \\
\hline \begin{tabular}{|l|l} 
Average hose temperature $\left({ }^{\circ} \mathrm{C}\right)$ \\
\end{tabular} & Life time $(\mathrm{h})$ & Life time (year) \\
\hline 120 & 28 & 0.003 \\
\hline 100 & 210 & 0.024 \\
\hline 80 & 2802 & 0.320 \\
\hline 60 & 50933 & 5.814 \\
\hline 40 & 1341027 & 153.085 \\
\hline 20 & 55181440 & 6299.251 \\
\hline
\end{tabular}

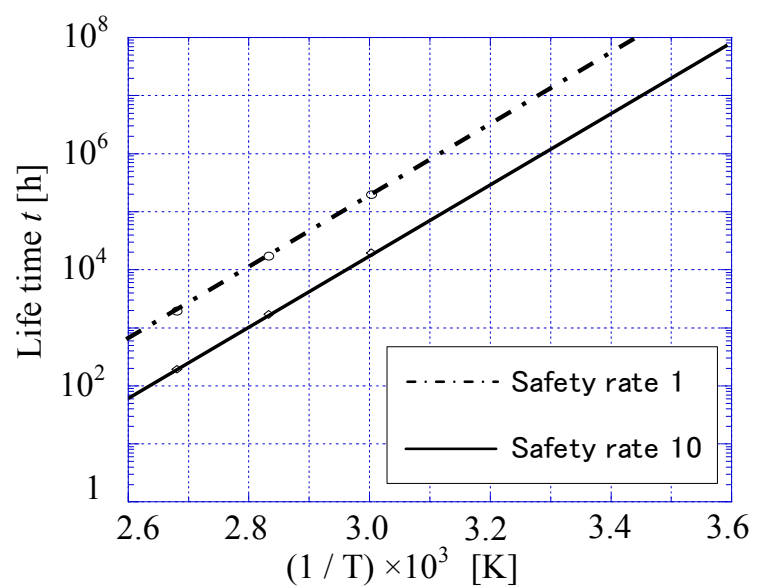

Fig.10 Arrhenius plot of inner rubber

\section{Conclusions}

Usually, automobile brake hoses were developed through investigating several actual prototype hoses experimentally. In this study, therefore FEM stress analysis has been applied to the caulked portion of hydraulic brake hose in order to promote, the development of the automobile hoses more effectively. The results are as follows.

(1) The reinforcement layer was assumed as an anisotropic elastic material with varying the elastic constants. Then, the thickness at the crimped portions coincides with the experiment with $10 \%$.The FEM results are found to simulate real brake hose accurately.

(2) The present analysis suggests that groove may cause high sealing performance since higher stress $\sigma_{\mathrm{n}}$ appears on the grooves. That may explain the experimental results indicating that 8 groove model has better sealing performance than the ones of 4 groove and no groove models.

(3) The maximum the normal stress $\sigma_{\mathrm{n}}$ for eight groove models is larger than the maximum $\sigma_{\mathrm{n}}$ for four groove models. The largest the normal stress $\sigma_{\mathrm{n}}$ at the No.8 groove may be effective for preventing oil leakage.

(4) The effect of this permanent deformation on the sealing performance was investigated. When the permanent deformation is $80 \%$, the normal stress is only about $20 \%$ of the value of no permanent deformation, and therefore may deteriorate the sealing performance seriously. 
(5) The lifetime estimation of the brake hose is attempted on the basis of the Arrhenius equation with the experimental results for compression set. It is found that the real lifetime can be roughly estimated by putting the safety factor as $\alpha=4 \sim 5$.

\section{Acknowledge}

The authors would like to thank Mitsubishi Motors Corporation and Meiji Flow Systems Co., Ltd. for providing valuable data of brake hose and useful discussions. Also we wishes to express our gratitude for advice of analysis received from $\mathrm{Mr}$ Yuichiro KUMAGAYA.

\section{References}

(1) Ishikawa, T., Hagiwara, H., Uno, A., Brake Hose with High Durability and Low-cost, Hitachi Cable, No.20 (2001), pp.137-142.

(2) Ono, M., Mizutani, S., Highly-Dulable Brake Hose with Low Expansion, Technical Report of Toyoda Gosei, Vol.48, No.1 (2006) , pp.30-31.

(3) Ishii, K., FEM Analysis for Crimp of Hydraulic Brake Hose, Technical Report of Meiji Rubber \& Chemical, Vol.44 (2003), pp.3-6.

(4) Kobayashi, Y., The Progress of Resisting Pressure for Car, Vol.63, No.9 (1990), pp.64-72.

(5) http://www.onk-net.co.jp/products/pdf/njgp_life.pdf. 